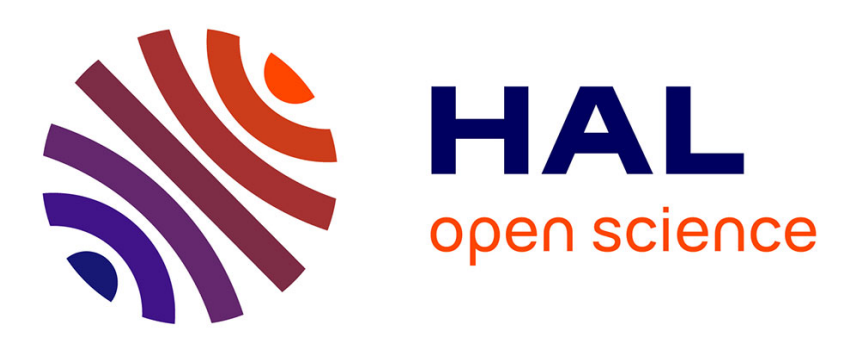

\title{
A micro-macro relationship for modeling the damage of discontinuous reinforced composites
}

\author{
N. Bourgeois, M. Keyvani, D. Baptiste
}

\section{To cite this version:}

N. Bourgeois, M. Keyvani, D. Baptiste. A micro-macro relationship for modeling the damage of discontinuous reinforced composites. Journal de Physique IV Proceedings, 1993, 03 (C7), pp.C7-1617C7-1622. 10.1051/jp4:19937253 . jpa-00251892

\section{HAL Id: jpa-00251892 https://hal.science/jpa-00251892}

Submitted on 1 Jan 1993

HAL is a multi-disciplinary open access archive for the deposit and dissemination of scientific research documents, whether they are published or not. The documents may come from teaching and research institutions in France or abroad, or from public or private research centers.
L'archive ouverte pluridisciplinaire HAL, est destinée au dépôt et à la diffusion de documents scientifiques de niveau recherche, publiés ou non, émanant des établissements d'enseignement et de recherche français ou étrangers, des laboratoires publics ou privés. 


\title{
A micro-macro relationship for modeling the damage of discontinuous reinforced composites
}

\author{
N. BOURGEOIS, M. KEYVANI and D. BAPTISTE*
}

Laboratoire MSS-MAT, URA 850 du CNRS, Ecole Centrale de Paris, Grande Voie des Vignes, 92295 Chatenay-Malabry cedex, France

* Laboratoire LM3, URA 1219 du CNRS, ENSAM, 151 Boulevard de l'Hôpital, 75013 Paris, France

\begin{abstract}
In discontinuous reinforced composites, different damage processes are observed : reinforcement fracture, interface debonding and matrix failure depending on the type of material and loading. So, local criteria of damage initiation were introduced in a micromechanical model to reproduce these phenomena and predict the material behavior. The model is based on the stiffness prediction by the Mori and Tanaka approach. Tensile stress-strain curves until total failure are simulated in the case of SMC type composite. The evolution with damage of all the elastic constants is also compared with ultrasonic measurements. In an $\mathrm{Al} / \mathrm{SiCp}$ composite, damage was identified to be particle fracture. Tensile behaviors with or without damage are compared. Three solutions to replace the broken particles are studied.
\end{abstract}

\section{INTRODUCTION}

Among several well-known micromechanical approaches the Mori-Tanaka [1] method is an alternative to find the estimates of elastic moduli and local stress-strain fields in multiphase composite materials. This method has been recently reformulated by Benveniste [2]. The main assumption of Mori-Tanaka's method was linked with Eshelby's original work [3].

The present paper is concerned with the simulation of damage induced effects on the elastic properties and the tensile behavior of two different composite materials with an elastic or a plastic matrix. Local damage mechanisms are identified by mechanical testing and observations. Initiation of damage and its evolution is simulated introducing local damage criteria in the Mori and Tanaka approach. Assumptions are also made on the equivalent behavior of the debonded or broken reinforcements.

\section{EXPERIMENTS}

\section{Materials}

In order to examine and model the damage mechanisms two different materials were selected.

The first one is a Sheet Molding Compound (S.M.C.) composite. $3 \mathrm{~mm}$-thick S.M.C. plates were manufactured by a Régie Renault research laboratory. The reinforcements are $10 \mu \mathrm{m}$-diameter and $2.5 \mathrm{~cm}$ long glass fibers. They were introduced in the form of bundles containing approximately 200 fibers. The bundles are more or less dispersed and randomly oriented in the plate plane. The matrix is a mixture of polyester resin and $\mathrm{CaCO}_{3}$ mineral charges. Due to the $2 \mathrm{D}$-random orientation, the composite as a whole is transversely isotropic.

The second one is spray formed $2618 \mathrm{Al}$ alloy reinforced with 15 vol.\% of Silicon Carbide (SiC) particles. Composite material and unreinforced alloy were supplied by Cospray (Alcan Int. Ltd) in the form of 
extruded rectangular bars (cross section $25.4 \mathrm{~mm}$ x $62.5 \mathrm{~mm}$ ). After extrusion, the bars were solution heat treated at $530^{\circ} \mathrm{C}$ for 1 hour, water quenched, and cold stretched up to $2 \%$. Afterwards, they were artificially aged at $190^{\circ} \mathrm{C} .10$ and 24 hours were necessary to reach peak-aged condition in the composite material and in the monolithic alloy, respectively.

In this composite, particles are approximately aligned with the extrusion direction. Their volume-averaged aspect ratio is 1.5 in the extrusion direction and their mean diameter is $12 \mu \mathrm{m}$. The matrix itself is a "composite material" because it contains small $\mathrm{Al}_{9} \mathrm{FeNi}$ intermetallic inclusions $(<2 \mu \mathrm{m})$.

\section{MORI-TANAKA THEORY FOR ORIENTED COMPOSITES}

\subsection{Effective elastic moduli}

The composite is assumed to be a continuous matrix reinforced with isotropic fibers. The reinforcements are assumed to be ellipsoidal inhomogeneities. A "phase" other than the matrix is defined as a collection of inhomogeneities whose orientation, aspect ratio, and elastic moduli are identical ; inhomogeneities of the same material but with a different orientation or aspect ratio therefore are classified as another phase. The matrix is denoted as the $o$ th phase, and a typical inclusion as the $r$ th one.

The basic equations are briefly mentioned. The composite stiffness tensor $\mathrm{L}$ is defined by :

$$
\begin{aligned}
& L=L^{0}\left\{I+\left(\sum_{r=1}^{r=n} c_{r} Q^{r}\right)\left(I+\sum_{r=1}^{r=n} c_{r}\left(S^{r}-I\right) Q^{r}\right)^{-1}\right\}^{-1} \\
& Q^{r}=-\left[\left(L^{r}-L^{o}\right) S^{r}+L^{o}\right]^{-1}\left(L^{r}-L^{o}\right)
\end{aligned}
$$

with $\mathbf{S}^{\mathbf{T}}$ is the Eshelby's tensor in the global coordinate system.

For an isotropic matrix, the components of Eshelby's tensor $\mathrm{S}^{\mathrm{r}}$ can be found in the book by Mura [5]. Eshelby [3] proved that the strain and stress fields are uniform within ellipsoidal inhomogeneities. $S^{r}$ is a function of the matrix Poisson's ratio and of the fiber aspect ratio.

$\mathrm{cr}$ is the volume fraction of $\mathrm{r}$ th phase. $\mathrm{n}$ is the total number of phases apart from the matrix.

I is the 4 th-rank identity tensor.

\subsection{Stress and strain tensor in each phase and at the interface}

The average strain in the matrix is equal to $E^{\circ}+\tilde{\varepsilon}$. where $\tilde{\varepsilon}$ is related to $\mathrm{E}^{\mathrm{O}}$ by :

$$
\tilde{\varepsilon}=\left[I+\sum_{r=1}^{r=n} \operatorname{cr}\left(S^{r}-I\right) Q^{r}\right]^{-1}\left[-\sum_{r=1}^{r=n} c_{r}\left(S^{r}-I\right) Q^{r}\right] E^{o}
$$

$\tilde{\varepsilon}$ and $\tilde{\sigma}$ are respectively the average perturbed strain and stress due to the presence of all the inhomogeneities in the matrix.

$\mathrm{E}^{\circ}$ is related to applied stress tensor $\Sigma$, by $\Sigma=L^{\circ} \mathrm{E}^{\circ}$. It is then possible to express the average strain in the matrix as a function of the prescribed stress.

On the other hand, the average strain in the fibers can be estimated from the average strain in the matrix.

$$
\bar{\varepsilon}^{\mathrm{r}}=\varepsilon^{\mathrm{r}}=\left(\mathrm{I}+\mathrm{S}^{\mathrm{r}}\left[\left(\mathrm{L}^{\mathrm{r}}-\mathrm{L}^{\mathrm{o}}\right) \mathrm{S}^{\mathrm{r}}+\mathrm{L}^{\mathrm{o}}\right]^{-1}\left(\mathrm{~L}^{\mathrm{r}}-\mathrm{L}^{\mathrm{o}}\right)\right) \bar{\varepsilon}^{\mathrm{o}}
$$

which is identical to : 


$$
\bar{\varepsilon}^{r}=\left[I+S^{r} L^{o-1}\left(L^{r}-L^{o}\right)\right]^{-1} \bar{\varepsilon}^{o}=T^{r} \bar{\varepsilon}^{o}
$$

Average stresses in the different phases are calculated through average strains and tensors of elastic moduli.

Although the eigenstrain $\varepsilon^{r}$ is discontinuous at all the interfaces. The displacement and the interfacial traction across the boundary must be continuous :

$$
\begin{aligned}
& u_{i}{ }^{\text {(out) }}-u_{i}{ }_{i}^{(\text {in) }}=0 \\
& \left\{\sigma_{i j}{ }^{\text {(out) })}-\sigma_{i j}{ }^{\text {(in) }}\right\} n_{j}=0
\end{aligned}
$$

$\mathrm{ni}$ is the unit outward normal of the fiber.

\section{DAMAGE MODELING}

\subsection{Local damage criteria in S.M.C. composite}

Two damage mechanisms were identified (Keyvani [4]) :

- fiber fracture which occurs when the maximum tensile principal stress ("Orp") reaches the fiber tensile strength ("Rf"),

- and interface debonding. Two different modes of interface failure are considered : failure by tension or by shearing. The debonding takes place when locally the normal or tangential interfacial stresses (" $\sigma_{i}$ " or " $\tau_{i}$ ") reach some critical value (" $\sigma i{ }^{\prime \prime}$ or " $T$ ic"). For each fiber orientation $\theta$ it is first necessary to know which is the most loaded interface. The normal vector at this interface is defined by the angle $\psi$. The stress vector at the interface is evaluated thanks to the continuity condition. Normal and tangential stresses are then obtained by projection of this vector.

"Gic" or "Tic" the interface strengths are unknown. So, the critical values were chosen as the matrix tensile strength (" $R \mathrm{~m}$ ") and the half of the latter (" $\tau \mathrm{m}=\mathrm{Rm} / 2$ "), respectively.

\subsection{Modeling of the damaged material}

The fiber contribution to the composite stiffness is changed after debonding or breaking. It has to be substituted by an equivalent reinforcement. The first solution consists in replacing a debonded fiber by the same volume of matrix. Consequently, the model probably gives an estimation of the damaged material behavior near the "lower bound".

At each modeling step a new composite material is defined, its stiffness tensor and the new damage threshold are estimated again. This new composite is identical to the undamaged one minus the fibers that were debonded during all the precedent steps. Thus, the computed stress-strain curve is a sequence of linear portions interrupted at each new damage threshold.

To determine which criterion is critical at each step, the three local stresses $\sigma_{\mathrm{rp}}, \sigma_{\mathrm{i}}$ and $\tau_{\mathrm{i}}$ are calculated and normalized with the critical values $R f, R_{m}$ and $\tau_{m}$, respectively.

Replacing the debonded fiber by matrix was the easiest solution. In fact, a debonded fiber still contributes to the material stiffness because of friction phenomena at the interface. The introduction of these phenomena in a micromechanical model is not easy, specially in composite with a complex geometry. A more realistic representation of damage is possible in the $\mathrm{Al} / \mathrm{SiCp}$ composite.

\subsection{Fractured particles in Al/SiCp composites}

The question is how to replace a broken particle. The damage is cracks that are in the particles and almost perpendicular to the tensile direction. Three solutions are tested : introducing a cavity, a penny-shape crack or an "anisotropic equivalent reinforcement" to replace the broken particle (Mochida and al.[6]). The first solution consists in replacing the fractured reinforcement with a cavity of the same geometry (aspect ratio 
and orientation). The second option consists in a substitution by a penny-shaped crack. The penny-shape diameter is equal to the particle one but the crack opening is not fixed. Thus, the effective crack volume fraction is a function of their opening and can be introduced as a parameter. The third alternative is the "anisotropic reinforcement". To take into account the fact that the crack is in the particle and not in the matrix, an "anisotropic equivalent reinforcement" is defined by the same elastic constants as the particle except in the tensile direction. Its compliance tensor is defined by :

$$
\begin{aligned}
& M_{1111}=M_{2222}=1 / E_{\mathrm{T}} \\
& M_{1122}=M_{1122}=-v_{\mathrm{r}} / E_{\mathrm{r}} \\
& \mathbf{M}_{1212}=1 / 2 G_{\mathrm{r}}
\end{aligned}
$$

all other components being zero.

Figure 1 represents Young's modulus variations with the volume fraction of broken particles. In this example undamaged composite is isotropic, the particles were assumed to be spheres.
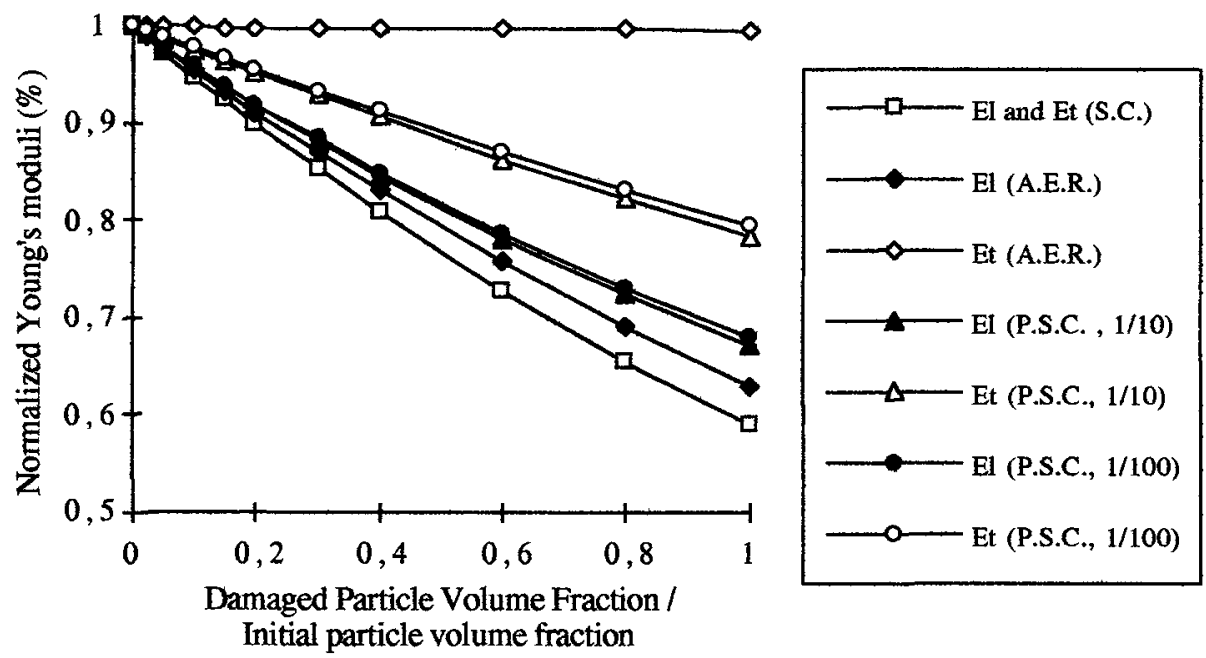

Figure 1 : Young's modulus variations as a function of "equivalent broken particle" type

- S.C. means "spherical cavity"

- A.E.R. means 'anisotropic equivalent reinforcement"

- P.S.C. means "penny-shaped crack" which is followed by $\mathrm{h} / \mathrm{d}$ the height over diameter ratio

As expected the replacement by a cavity gives the highest modulus decrease. Note that in this configuration the damaged composite is still isotropic, which is probably wrong. In the two other cases the damaged composite is no longer isotropic. The main difference between penny-shape crack and "anisotropic equivalent reinforcement" solutions is their influence on the transverse modulus. The anisotropic inclusion keeps this modulus constant.

In the three cases the composite is a matrix reinforced with two reinforcement phases. Introducing simultaneously aligned reinforcements with different shapes (aspect ratio) has been reported by Weng [7] to be one of the cases when Mori-Tanaka estimated stiffness tensor has no diagonal symmetry. Only the substitution of the fractured particle by a penny-shape crack gives a non-symmetric tensor.

\section{COMPARISON OF SIMULATIONS AND MEASUREMENTS}

\subsection{S.M.C. composite material}

Under prescribed deformation simulated tensile test is reported on Figure 2 and superposed with experimental data. As expected the simulation underestimates the damaged material behavior despite the good prediction of the initial Young's modulus and that of damage initiation. 


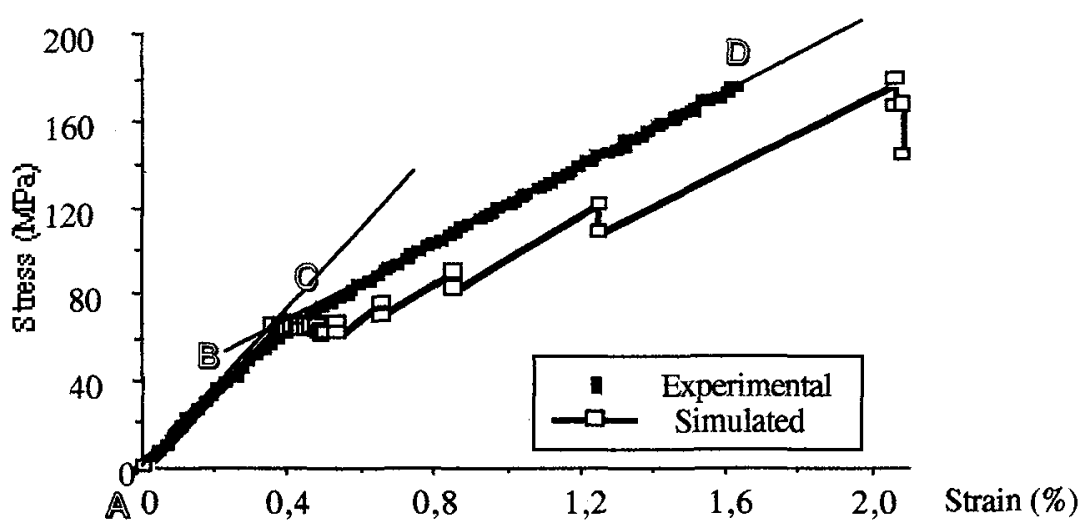

Figure 2 : Experimental and simulated S.M.C. tensile stress-strain curves.

As it was said previously, the evolution of elastic constants with damage was evaluated by ultrasonic technique. Nevertheless, that the composite, initially transversely isotropic, becomes orthotropic with damage prevents from a total characterization of the material. Only seven of the nine elastic moduli are measurable. Figure 3 reproduces the comparison between measurements and computations. Replacing the debonded or broken fibers by matrix leads to variable agreement with experimental data.
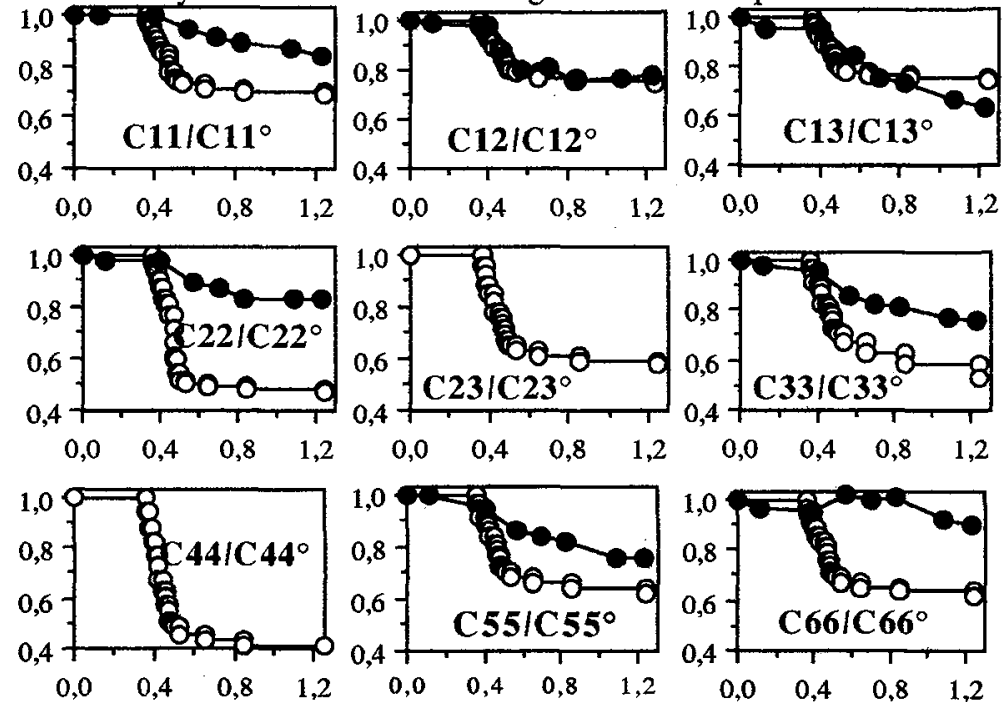

Figure 3 : Simulated and US measured elastic constants evolutions with damage $\left(\varepsilon_{33}(\%)\right)$

measured ; $O$ simulated

Indications are also gathered on the local damage mechanisms. Part $\mathrm{BC}$ of the stress-strain curve is probably due to a rapid succession of interfacial debonding on all the fibers with an orientation larger than 30 degrees. Other fiber debondings require higher stress level (zone CD). The final failure occurs through the failure of the fibers that are approximately aligned with the tensile direction.

\subsection{Al/SiCp composite material}

To define if damage has an effective influence on the behavior of $\mathrm{Al} / \mathrm{SiCp}$ studied material, it was first essential to introduce matrix plasticity effect. Tandom and Weng [8] developed the Mori-Tanaka method with a plastic matrix by using the concept of secant moduli. Input data are the matrix stress-strain curve, each phase elastic moduli and the phase volume fractions. Experimental and simulated stress-strain curves are shown on Figure 4. From these results it can be concluded that damage plays a minor role in the overall tensile behavior of the composite. 


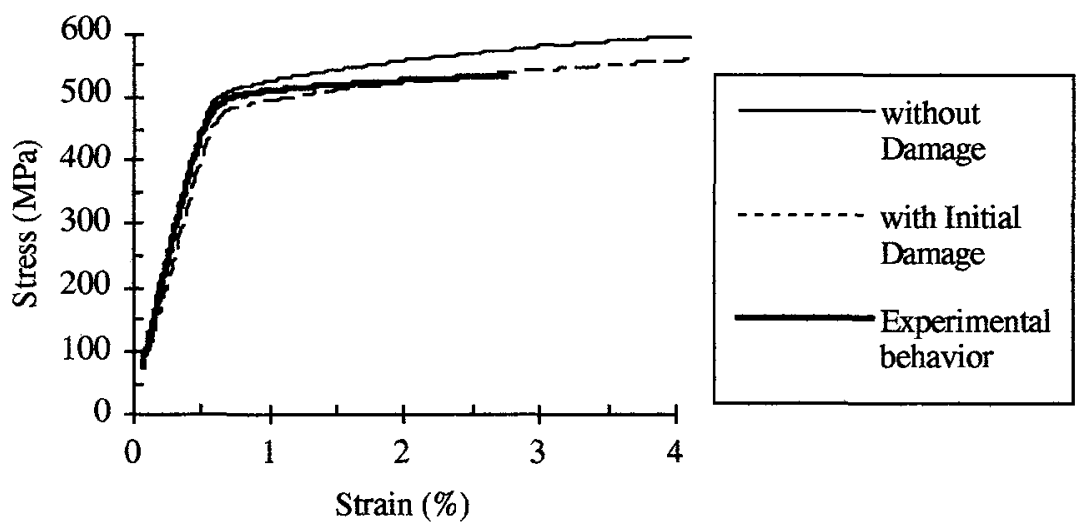

Figure 4 : Experimental and simulated $\mathrm{Al} / \mathrm{SiCp}$ tensile stress-strain curves.

$25 \%$ of broken particles are needed to reproduce the longitudinal Young's modulus decrease measured at a strain corresponding to the beginning of necking. A simulation of the material behavior with an initial volume fraction of fractured particles as estimated above is reproduced on Figure 4. Here the replacement by an "anisotropic equivalent reinforcement" was used, but the result in the longitudinal direction is almost independent of the substituted reinforcement. As expected, the initial Young's modulus is now underestimated but lower stress levels are reached.

New developments have begun to introduce an evolution of the number of fractured particles as the load increase.

\section{CONCLUSION}

Local damage criteria coupled with the Mori-Tanaka approach were used to simulate the elastic behavior and damage of a SMC composite. While replacing a debonded or broken fiber by matrix is a rough approximation, modeling results and ultrasonic or tensile experiments are in reasonable agreement.

On the other hand, three solutions for the replacement of a broken particle in an A1/SiCp composite were compared. Among the three alternatives, only two tend to reproduce the damage induced anisotropy. Among the last two solutions, little difference was detected in the loading direction contrary to the transversal one. Unfortunately, measurements of the transverse decrease in moduli are not available. It would also be profitable to quantify the volume fraction of broken particles by image analysis. In fact, compared to matrix plastic behavior, damage seems to have a slight effect on the overall tensile behavior of this composite.

\section{REFERENCES}

1 - Mori T. and Tanaka K., "Average Stress in Matrix and Average Elastic Energy of Materials with Misfitting Inclusions", Acta Metall., Vol. 21, 1973, pp.571-574.

2 - Benveniste Y., "A New Approach to the Application of Mori-Tanaka's Theory in Composite Materials", Mechanics of Materials, Vol. 6, 1987, pp. 147-157.

3 - Eshelby J.D., "The Determination of the Elastic Field of an Ellipsoidal Inclusion, and Related Problems", Proc. R. Soc. London, Vol. A241, 1957, pp. 376-396.

4 - Keyvani M., "Contribution à la Caratérisation Micromécanique et Ultrasonore du Comportement et de l'Endommagement des Composites de type SMC (Sheet Molding Compound", Thèse de l'Ecole Centrale de Paris, 1992.

5 - Mura T., "Micromechanics of Defects in Solids", Second revised edition, Martinus Nijhoff Publishers, 1987, pp. 67-84.

6 - Mochida T., Taya M. and Obata M., "Effect of Damaged Particles on the Stiffness of a Particle / Metal Matrix Composite”, JSME Int. Journal, Series I, Vol. 34 n², 1991, pp. 187-193.

7 - Weng G.J., "The theoretical connection between Mori-tanaka's theory and the Hashin-Strikman bounds", Int. J. Eng. Science, Vol. 28, 1990, pp. 1111-1120.

8 - Tandon G.P. and Weng G.J., "A theory of particle-reinforced plasticity", J. of Applied Mechanics Trans. of ASME, Vol. 55, 1988, pp. 126-135. 